\title{
VII. PHYSICAL GROWTH AND MATURATION FOLLOWING EARLY SEVERE INSTITUTIONAL DEPRIVATION: DO THEY MEDIATE SPECIFIC PSYCHOPATHOLOGICAL EFFECTS?
}

By Edmund J. Sonuga-Barke, Wolff Schlotz \& Michael Rutter

\section{$<\mathbf{H 1}>$ Introduction}

Our previous work (Rutter et al., 2007) and the data reported in the preceding chapters of this monograph (chapter 4; Kreppner et al.) provide conclusive evidence of the persistent nature of the negative impact of early severe deprivation. Institutional deprivation, despite the good outcomes for many, was often associated with substantial impairment and disorder across a wide range of psychopathological domains at all follow-up ages. We have argued previously that this degree of persistence despite adoption into well functioning and nurturing families (chapter 8; Castle, Beckett, Rutter \& Sonuga-Barke). Also, the considerable degree of continuity of problems seen at the level of individual cases (Kreppner et al., 2007), provides strong prima facie evidence that the effects of deprivation are associated with early established and fundamental neurobiological alterations (Mehta et al., 2009), although it remains to be seen what specific brain mechanisms are involved and whether different neurobiological components have specific effects on outcomes.

There are a number of general mechanisms through which deprivation-related early adversity might operate to produce such long lasting effects (Rutter \& O’Connor, 2004). Children who spent their early years in the Romanian institutions were exposed to multiple putative risks of diverse kinds (chapter 1; Rutter, Sonuga-Barke \& Castle). The very poor quality and quantity of food provided, reflected in the substantial levels of subnutrition found amongst adoptees at the time of entry into the 
UK, placed the children at nutritional risk (Sonuga-Barke et al., 2008). There were also severe psychosocial risks linked to the low levels of social contact and emotional support, and intellectual deprivation associated with a lack of stimulation (Castle et al., 1999). These risks were, if anything, more pervasive than the nutritional risks (Sonuga-Barke et al., 2008). Although, in some ways, the effects of subnutrition represent the most obvious candidate source of long term biological risk, both the experimental/animal and the clinical literatures support a role for both nutritional and the psychosocial/cognitive components of early deprivation as putative causes of longterm negative outcomes. Subnutrition inhibits brain growth and development during the early years of life (Golden, 1994; Graham \& Adrianzen, 1972; Liu, Raine, Venables, Dalais, \& Mednick, 2003; Martorell, Khan, \& Schroeder, 1994; Stoch, Smythe, Moodie, \& Bradshaw, 1982), and is associated with both intellectual impairments and general mental health problems (Liu \& Raine, 2006; Liu, Raine, Venables, \& Mednick, 2004).

The negative effects of psychosocial and cognitive deprivation have been studied in both patient populations (Pears \& Fisher, 2005; Teicher et al., 2003) and in animal models (de Kloet, Sibug, Helmerhorst, \& Schmidt, 2005; Rosenzweig \& Bennett, 1996). These studies show that early exposure to impoverished environments is associated with smaller brains, altered brain structure and function, even after taking account of nutritional level. Candidate mechanisms for nutrition-related effects include reduced overall processing capacity (Ivanovic et al., 2004), and neuralenergetic resources (Levitsky, 1979).

Models of psychosocial effects focus either on some form of biological programming during a critical period of early development, or on early sustained neurobiological insult or dysregulation associated, perhaps, with damaging effects of 
exposure to stress hormones (Leon-Carrion et al., 2009). With respect to programming mechanisms, Rutter and O'Connor (2004) have highlighted the effects of experience-expectant (whereby certain experiences are required for normal development) or experience-adaptive (the brain adapts to the circumstances operating during critical periods) mechanisms.

A recent report of outcomes up to age 11 years presented a study of the relative contributions of nutritional risk and psychosocial risk to physical growth and psychopathological outcomes following early institutional deprivation in the English and Romanian Adoptee (ERA) study sample (Sonuga-Barke et al., 2008). In particular, the extent to which stunted physical growth as expressed in relation to reduced brain size (indexed by head circumference) might provide an indication of a neurobiological mediator of nutritional and psychosocial risk, was examined. In the absence of more direct measures or specific physiological markers of nutritional status during the period of institutionalization, the definition of subnutrition was based on measures of weight at the time of entry into the UK, standardized in relation to UK norms. Note that this comparison does not assume that psychosocial factors play no role in subnutrition. On the contrary, they are clearly associated. The 'rationale' is simply that if, despite this, the body weight is normal, psychosocial deprivation must be operating through some mechanism other than low calorie intake. Obviously, the normal weight cannot rule out either a damaging imbalance in nutritional provision or specific nutritional deficits. Hence, our use of the term 'subnutrition' and not 'malnutrition'.

This allowed us to compare the outcomes for subnourished and non-subnourished children as a function of age of entry to the UK (a measure highly predictive of the duration of deprivation experienced - our index of psychosocial deprivation). In 
particular, we expected the effects of subnutrition to be apparent through body growth, effects that are probably established relatively early and quickly. Thus, subnutrition effects on outcomes were likely to occur after only a short period in institutions, and to be present prior to the 6 month threshold of risk used in this monograph. On the other hand, we expected effects of psychosocial deprivation to operate somewhat independently of these physical growth factors and take longer to establish.

The results were striking and somewhat unexpected. First, there were very different growth trajectories for weight and head circumference; with apparent catchup in weight seeming to be largely complete by 11 years of age irrespective of duration of deprivation and subnutrition. There was substantially less catch-up in head circumference, and this occurred more slowly with still substantial effects for the most deprived and subnourished children persisting to age 11 years. This differential pattern was consistent with a recent meta-analysis based on cross-sectional rather than longitudinal data (Juffer \& van IJzendoorn, 2009; van IJzendoorn, BakermansKranenburg, \& Juffer, 2007). Crucially, head circumference was not substantially reduced in the non-subnourished group with less than 6 months deprivation. By contrast, subnourished children, and even those without subnutrition but who had experienced more than 6 months deprivation, exhibited substantial stunting. Psychosocial risk of sufficient duration apparently had an effect on brain development that was independent of nutritional risk, at least as indexed by weight at entry to the UK. Second, duration of deprivation had a major impact across all outcomes measured right up to age 11 years (cognitive impairment [CI], quasi-autism [Q-A], disinhibited attachment [DA] and inattention/overactivity [I/O]). Substantial effects of subnutrition were restricted to IQ. Third, although head size was associated with all 
outcomes - (with strongest effects for CI and DA) - it did not appear to mediate either psychosocial or nutritional risk processes.

There are a number of possible interpretations for the surprising failure to find evidence for a mediational role for head circumference. First, we can rule out the possibility that head circumference does not provide a valid measure of brain growth and stunting as in our structural imaging pilot findings (Mehta et al., 2009, described below) they were highly correlated. Second, the lack of mediation by gross brain size does imply that more specific and subtle neural alterations in structure and function with associated altered patterns of regulation of neurochemical processes are important mediators of outcome. Indeed, this is highly probable. The power of the psychosocial environment to impact on specific brain processes during development is well established through animal models (Nelson, 1999).

Technological advances have made it possible to explore effects of deprivation directly through structural and functional imaging. The limited imaging work carried out to date in institutionalized samples has focused on components of the limbic system hypothesized, on the basis of work in animals and other clinical samples (e.g., abuse and neglect), to be especially sensitive to early adverse and stressful experiences; the hippocampus, amygdala and corpus callosum (Bremner, 1999, 2001, 2007; Bremner, Elzinga, Schmahl, \& Vermetten, 2008; Bremner et al., 1995; Bremner et al., 1997; De Bellis et al., 2002; Eluvathingal et al., 2006; Karl et al., 2006; Kaufman, Plotsky, Nemeroff, \& Charney, 2000; Suomi, 1997; Teicher et al., 2004; Tupler \& De Bellis, 2006; Vythilingam et al., 2005). Most studies have focused on adverse events in middle childhood, adolescence and adulthood. The specific effects of very early deprivation in humans are not known. However, the period of early deprivation studied within our cohort coincided, more generally, with a period of 
known dramatic growth in these areas (Hayakawa et al., 1989; Nishida et al., 2006; Pfluger et al., 1999). To study this, we used magnetic resonance imaging (MRI) to measure these three key brain regions in a pilot study (Mehta et al., 2009). We compared 14 ERA children who had experienced more than 6 months of deprivation with a group of non-institutionalized controls $(n=11)$. As expected, total gray and white matter volumes were significantly smaller in the institutionalized group and, after correcting for these differences, the institutionalized group had a greater amygdala volume (reaching statistical significance for the right hemisphere). There were no differences in the volume of hippocampal or corpus-callosal regions. This finding fits in with a small, but growing, literature supporting differences in amygdala in children suffering early institutional deprivation.

Reports from a small scale study, with notable methodological limitations, provided the first evidence in this regard. Institutional deprivation was associated with reduced metabolism in the left orbito-frontal cortex and left medial temporal lobe area (including hippocampus and amygdala; Chugani et al., 2001) using positron emission tomography. Second, reduced white matter integrity was found in the uncinate fasciculus, which connects the inferior frontal lobe with the anterior temporal lobe areas including the amygdala (Eluvathingal et al., 2006) using diffusion tensor imaging. Most recently, in a much larger study $(n=78)$ Tottenham and colleagues (in press) used MRI to explore limbic regions in a group of children adopted from institutions. Although they did not find reductions in total brain volume, they confirmed the finding of larger amygdala, extending this finding to show an association with duration of institutional care and also a correlation with poor emotion regulation as assessed by laboratory tests. There was no association between amygdala volume and the presence of an anxiety disorder, however. These studies 
together highlight the potential importance of altered limbic structures in explaining residual problems in institution-reared children.

A third possible interpretation of the failure to find a mediating role for overall brain size, is that brain size does in fact mediate the effects of deprivation but that these mediating effects were not picked in our analysis because of the way that the sample was characterized with regard to intellectual impairment and psychopathological outcomes. In particular it might have been that the analyses were not optimized to analyze deprivation-specific processes described in chapters 3 (Kumsta, Kreppner, Rutter et al.) and 4 (Kreppner, Kumsta, Rutter et al.) of the current monograph. Inevitably, the group of children studied was extremely heterogeneous in terms of the presence of deprivation-related problems. Whereas some of the problems expressed by individuals were almost certainly caused by earlier deprivation, others were almost certainly not. Thus, for instance, in chapter 3 (Kumsta, Kreppner et al.), we argued that whereas Q-A was almost exclusively a DSP, I/O and CI were only to be considered DSPs if certain conditions were met (i.e., if they occurred in association with Q-A and/or DA). This meant that I/O and CI outcomes, for instance, were influenced by both deprivation-specific and non deprivation-specific elements. Because in the Sonuga-Barke et al. (2008) paper, Q-A symptoms were based on the Social Communication Questionnaire (SCQ) scores, rather than the clinical assessment used in the current monograph and in previous papers (Rutter et al., 2007), this is likely to be so for the Q-A analysis as well as the I/O, CI and DA analyses. Given that deprivation-related processes mediated by altered patterns of brain growth might operate exclusively in relation to DSPs, the inclusion of non-DSP cases could only dilute the statistical effects. In this chapter, we refine the analysis presented in Sonuga-Barke et al. (2008) by distinguishing DSP and non-DSP problems and by 
focusing specifically on the outcomes defined as DSP according to the definition set out in chapter 3 (Kumsta, Kreppner et al.).

One complicating factor in the current analyses that was less relevant at the age 11 year follow-up is puberty. There is evidence in the literature that adverse early lifeevents and associated environmental stressors may alter the timing of puberty (Posner, 2006), with children exposed to psychosocial stress having significantly earlier puberty (Belsky et al., 2007; Hulanicka, Gronkiewicz, \& Koniarek, 2001). In keeping with this picture, children adopted from abroad have been found to reach puberty earlier than their UK counterparts; an effect that is not explained by genetic differences (Baron, Battin, David, \& Limal, 2000). Although the neuroendocrine mechanism responsible for premature puberty has yet to be identified, central nervous system reprogramming has been highlighted as a possible focus for future study (Domene et al., 2007). On the basis of these and other data, we would expect children exposed to severe early deprivation in the sample studied in this monograph to be at increased risk of entering puberty prematurely. Early puberty has been implicated in an increase in psychological problems during the teenage years (Mrug et al., 2008) and is also associated with an early growth spurt (Aksglaede, Olsen, Sorensen, \& Juul, 2008). On the basis of these findings, we anticipated that children with extended periods of institutional deprivation would pass through puberty earlier than the comparison group and show an earlier growth spurt. The current sample includes similar numbers of males and females and so provides a good opportunity: i) to see if gender-related differences in the timing of puberty are found with our measures and are also reflected in an earlier growth spurt; ii) to see whether these gender-related effects are altered by institutional deprivation.

\section{$<$ H1 $>$ Aims}


(i) To plot developmental trajectories for weight, height and head circumference into mid-adolescence for those experiencing more than six months deprivation ( $>6 \mathrm{M}$ ) compared to pooled comparison group (as defined in chapter 3; Kumsta, Kreppner et al.).

(ii) To test whether the DSP group was differentially affected in terms of physical growth, even after controlling for age at entry to the UK.

(iii)To examine the role of subnutrition in DSP and non-DSP physical growth trajectories.

(iv) To explore the extent to which the effects of duration of deprivation and subnutrition on DSP was mediated by head circumference at age 6 years.

(v) To examine the impact of institutional deprivation on the timing of puberty and the extent to which early puberty might be related to growth trajectories in those exposed to extended deprivation.

\section{$<H 2>$ Analytical strategy}

The analytical strategy followed the basic principles set out in chapter 2. Mixed effects regression models were used to test for differences in growth trajectories between the various groups specified in the aims. Subnutrition was introduced as a factor using the same threshold as previously defined (i.e., $1.5 S D$ below the UK norm for weight at age of entry into the UK; Sonuga-Barke et al., 2008). This cut-off was chosen because it was crucial for us to identify a group with nutritional status within the normal range. Puberty was assessed using the Tanner scales (see chapter 2) at age 11. Mediational analyses were computed using the same path models as described in chapter 2.

\section{$<$ H1 $>$ Results}

Preliminary analyses supported the combining of the UK adoptees, noninstitutionalized Romanians and the institutionalized Romanians who entered the UK 
before 6 months $(<6 \mathrm{M})$ into one large comparison group. With the exception of smaller head circumference $s d$-scores, in the Romanian children at age 6 years (markedly smaller for the $<6$ month Romanian group) there were only group differences for height and head circumference $\left(F^{\text {Height }}[2,112]=3.53, p=.033, \eta^{2}=\right.$ $\left..059 ; F^{\mathrm{HC}}[2,112]=7.25, p=.001, \eta^{2}=.115\right)$. The three subgroups also did not differ in terms of stage of puberty at age $11, F(2,110)=1.17, p=.32, \eta^{2}=.021$, again justifying their pooling into one larger comparison group.

$<H 2>$ Do the differential patterns of catch-up for weight, height and head circumference in children experiencing extended deprivation continue into adolescence?

Table 7.1 reports the means and standard deviations for measures of weight, height and head circumferences at 6,11 and 15 years as a function of gender and membership of the $>6 \mathrm{M}$ group. Figures $7.1 \mathrm{a}$ and $7.1 \mathrm{~b}$ illustrate the growth trajectories for height and weight and 7.1c for head circumference. In interpreting these effects, it must be borne in mind that there had already been considerable catch-up in growth between entry to the UK and the 6 year assessments with apparently almost complete catch-up for height and weight. There was partial catch-up for head circumference by age 6 years and this continued but remained incomplete up to 11 years. According to the current analyses, a striking and unexpected change in growth trajectories for both height and weight occurred between 11 and 15 years. This led to a complicated set of effects across age for the different study groups as represented by the significant interaction between group and age at testing $\left(F^{\text {Height }}[2,257.7]=10.48, p<.001\right.$; $\left.F^{\text {Weight }}[2,268.2]=4.83, p=.009\right)$.

Trajectories for height and weight displayed some important similarities and so will be discussed together. The comparison group displayed a steady growth 
trajectory from 6 through to 15 with slight, but insignificant, growth acceleration relative to the population as a whole during that period with height and weight around the UK norms at all testing points. This pattern is as would be expected in nondeprived samples and provides further evidence for the validity of the $6 \mathrm{M}$ threshold for deprivation-related risk. The $>6 \mathrm{M}$ group showed a very different pattern with significant growth acceleration between 6 and 11 (although the means were still below UK norms at age 11), followed by an equally marked pattern of growth deceleration between ages 11 and 15 ( $p s<.001)$. This meant that the relative gains made by 11 years were lost in the subsequent 5 years. In fact, on average height and weight, the effects of group were larger at 15 than 6 years. Thus, some of the apparent catch-up between 6 and 11 identified in this (and other) studies might actually represent a transient change in growth trajectory rather than permanent acceleration (i.e., catchup).

The pattern for head circumference growth trajectories were very different to those seen for height and weight. Overall the two groups differed by a similar degree at all testing ages (all $p \mathrm{~s}<.001$ ) and there was a general pattern of growth acceleration for both groups. However, there was no interaction between group and age of testing $(F[2,270.4]=1.09, p=.34)$ : The trajectories for the two groups were almost parallel . Both groups displayed significant accelerated growth towards the UK norm between 6 and 11 years of age (both $p \mathrm{~s}<.001$ ). Whereas the patterns of accelerated growth for the comparison group between 11 and 15 years was not significant $(p=.11)$, it was significant in $>6 \mathrm{M}$ group $(p=.001)$. Despite this, the $>6 \mathrm{M}$ group remained clearly small for its age in terms of head circumference $(s d$-score $=-0.91)$ and significantly below the comparison group $(p<.001)$.

TABLE 7.1 about here 


\section{FIGURES 7.1a-c about here}

$<H 2>$ Did patterns of physical growth in those children who experienced more than 6 months deprivation vary as a function of DSP?

Table 7.2 shows the growth characteristics for the DSP+ and DSP- >6M groups compared with the comparison group. The trajectories of the three groups are significantly different (age of testing x group: $F^{\text {Height }}[4,254.3]=5.77, p<.001 ; F^{\text {Weight }}$ $[4,265.5]=3.32, p=.011)$, and the overall mean levels differed between groups (main effect group: $F^{\text {Height }}[2,200.7]=14.35, p<.001 ; F^{\text {Weight }}[2,202.4]=12.68, p<$ .001 ). Figures 7.3a and 7.3b illustrate the findings for data for height and weight. As can be seen, the characteristic growth pattern in the $>6 \mathrm{M}$ group (i.e., marked acceleration between ages 6 and 11 years and marked deceleration between 11 and 15 years) is seen to an almost identical degree for the DSP+ and DSP-group. However, the overall growth reduction is greater for the DSP+ group at all three time points for both height (all $p<.001$ ) and weight (all $p \leq .001$ ). For the DSP-group, these effects were most strongly present at age 15 years $(p s<.003)$, but not present at 6 ( $p s>.051)$ or $11(p s>.88)$ years. As far as the effects for head circumference (see Figure 7.2c) are concerned, once again the upward trajectory of growth across ages is similar for $\mathrm{DSP}+$ and DSP- (time $\mathrm{x}$ group: $F[4,267.1]=0.68, p=.61$ ). However, the most substantial overall effects of deprivation are restricted to the DSP+ group (all $p<$ $.001)$, whereas the effects for the DSP-group are marginal at ages $6(p=.015)$ and 11 $(p=.07)$, and were not present at age $15(p=.23)$.

TABLE 7.2 about here FIGURES 7.2a-c about here

$<H 2>$ What role did subnutrition play in the effects of deprivation on growth? 
$<H 3>$ Height and weight: For this analysis, the comparison group consisted of Romanian children who entered the UK before 6 months of age and the group of non-institutionalized Romanian adoptees ( $n=64$; to the best of our knowledge there was no subnutrition in the UK group). Figures $7.3 \mathrm{a} / \mathrm{b}$ and $7.3 \mathrm{c} / \mathrm{d}$ show the growth effects for height/weight for these three groups as a function of subnutrition. There was an overall effect of subnutrition on height $(F[1,124.7]=9.19, p=.003)$, and weight $(F[1,125.0]=13.03 ; p<.001)$, with the expected 'acceleration-deceleration' pattern being present to a greater or less degree in both $>6 \mathrm{M}$ groups. This effect of subnutrition could still be seen at age 15 years. There was no differential effect of subnutrition as a function of group membership (group x subnutrition: $F^{\text {Height }}[2$, $\left.124.4]=1.18, p=.31 ; F^{\text {Weight }}[2,125.1]=1.21, p=.30\right)$. Nevertheless, the pattern of results highlights a number of interesting findings. First, deprivation of over 6 months duration was associated with growth stunting even in the absence of subnourishment. Second, the characteristic growth patterns of acceleration-deceleration in the $>6 \mathrm{M}$ group were seen irrespective of whether the children were subnourished. Third, the differential patterns of stunting in the three groups were somewhat different in subnourished and non-subnourished groups. Both the comparison group and the DSP+ group showed substantial differential stunting in the subnutrition group whereas the DSP- group showed similar effects whether they were subnourished or not. This meant that the effects of extended deprivation on physical growth were limited to those with DSPs following subnourishment - those children most affected in terms of intellectual functioning and psychopathology also seemed especially vulnerable to the effects of subnutrition. 
$<H 3>$ Head circumference: This differential pattern in the DSP- group for subnourished and non-subnourished groups was even more apparent with regard to head circumference (fig 7.3e/f) with almost complete overlap between this group and the comparison group in the presence of subnutrition and complete overlap between DSP+ and DSP- in the non-subnourished groups. Table 7.3 displays the proportion of participants in the $>6 \mathrm{M}$ group in the $\mathrm{DSP}+$ group as a function of sub-nourishment. Subnutrition did not increase the risk of the development of DSPs in the $>6 \mathrm{M}$ group $(O R: 0.92 ; p=.88)$. Similarly, subnutrition did not increase the risk of developing any of the sub-components of DSPs (Q-A: OR: $1.54 ; p=.55$; DA: OR: $1.02 ; p=.97$; CI: OR: $1.64 ; p=.41 ; \mathrm{IO}:$ OR: $2.06 ; p=.39$ ).

\section{FIGURE 7.3e-f about here}

\section{TABLE 7.3 about here}

$<H 2>$ Does stunting of brain growth mediate the effects of duration of deprivation on DSPs?

Figure 7.4 illustrates the results of the mediational path analysis for DSP group membership as a whole, and for the two DSP elements - Q-A, DA (I/O and CI could not be computed because of empty cells). In each case, there was a strong direct effect between duration of deprivation and outcome in the unmediated model and this remained significant when head circumference at age 6 years was introduced into the models as a second pathway. However, in the case of DSPs overall, and DA in particular, there was also a highly significant indirect path via head circumference. This pathway, although less important than the direct pathway, did account for approximately $20 \%$ of the total effect of duration of deprivation on DSP and DA. This provides the first direct evidence that overall brain growth plays a partial mediating role with regard to psychological outcomes following early deprivation. There was no 
role for head circumference as a mediator of Q-A, mainly due to a lack of an initial association between head circumference and Q-A.

\section{FIGURE 7.4 about here}

\section{$<H 2>$ Is institutional deprivation related to the early onset of puberty?}

Associations of deprivation with onset of puberty were tested using two indicators: a) stage of puberty at age 11 as reported by the parents on the Tanner scale (see chapter 2) treated as a continuous variable; b) categorized as 'early onset of puberty' or 'not early onset of puberty' based on the $80^{\text {th }}$ percentile of the continuous measure of stage of puberty at age 11 years (we initially planned to use the $85^{\text {th }}$ percentile cut-off, but the $80^{\text {th }}$ was the nearest that allowed use of a whole number cutoff). As there was some variation in the age of the children at the time of the parent interviews, all puberty analyses were adjusted for the exact age of the child at the time of the interview. The valid numbers in the puberty analyses were 112 for the pooled comparison group, 85 for the total $>6$ months institutionalized group, 45 for the DSP-, and 40 for the DSP+ group. Table 7.4 shows the frequencies.

In order to assess the sensitivity of our measures of puberty, we compared the stage of puberty and the percentage of children with early puberty at age 11 for male and female participants in the comparison group. As expected, more girls (27\%) than boys $(9 \%)$ showed signs of puberty at age $11($ OR: $0.28 ; p=.018)$, and the average stage of puberty was significantly higher in girls $(M=3.80 ; S D=1.83)$ than in boys $(M=3.08 ; S D=1.20 ; \beta=-.23 ; p=.013)$. We then compared whether these gender differences were also seen in the $>6 \mathrm{M}$ group. The gender differentiated pattern was similar in the $>6 \mathrm{M}$ group, although the male-female difference was less and fell short of statistical significance, both with regards to early puberty (girls: $31 \%$; boys: $21 \%$; 
OR: $0.64 ; p=.39$ ) and average stage of puberty at age 11 (girls: $M=4.33 ; S D=2.30$; boys: $M=3.42 ; S D=1.39 ; \beta=-.20 ; p=.061)$.

We went on to examine the effects of institutional deprivation on the stage of puberty reached by age 11 comparing first the total group of individuals who had experienced institutional deprivation lasting beyond the age of 6 months, and the pooled comparison group. The mean of 4.02 in the institution-reared group (see table 7.4) was about one third of a standard deviation higher than the 3.38 in the pooled comparison group - a statistically significant difference $(\beta=.117, p=.017)$. Accordingly, there was good evidence that institutional deprivation was associated with earlier pubertal development. However, within the institutional group there was no appreciable difference according to the presence or absence of DSPs. The figures for the proportions in the groups having an early puberty followed the same pattern (27\% in the institution-reared group $v s .17 \%$ in the pooled comparison group) - a difference that fell short of statistical significance due to the reduced power of categorical comparisons compared with dimensional ones $(O R: 1.77, p=.11)$, but, nevertheless, a substantial difference of a similar kind. It should be noted that two of the early developers in the institutional group had been treated several years before 11 in order to postpone puberty.

\section{TABLE 7.4 about here}

$<H 3>$ Growth trajectories and puberty: To test whether the characteristic acceleration-deceleration pattern in height and weight trajectories was due in part to puberty-related effects, the growth trajectories for those that had and had not reached puberty by age 11 were compared across the DSP+, DSP- and comparison groups. Unfortunately, these analyses were underpowered, but figure 7.5 shows markedly different growth trajectories as a function of puberty onset by age 11, with the 
acceleration-deceleration pattern being particularly characteristic of the early puberty group. Although the three-way interactions failed to reach significance (all $p \mathrm{~s}>.18$ ), post-hoc comparisons within the early puberty group revealed significant changes within groups between all successive assessment waves in height and weight, whereas there was only marginal change within groups when puberty had not been reached by age 11 .

In those who had not reached puberty by age 11 , there was no accelerationdeceleration pattern, whereas for the early maturing individuals this pattern was evident for height and weight, except that there was a plateau rather than a deceleration after age 11 for head circumference. Adolescents with a DSP and no early puberty were smaller (height, weight and head circumference) than the comparison group by age 15 . However, this comparison was not significant for those DSP+ adolescents who did show early puberty. Interestingly, suggestions of the acceleration-deceleration pattern can be seen for the first time in the comparison group who had early onset puberty for height and weight - highlighting the role of puberty even outside the effects of deprivation.

\section{FIGURE 7.5a-f about here}

$<H 3>$ Gender difference in growth trajectories: We next examined the effects of gender on growth spurt. The results showed that the deceleration of growth shown in Figure 7.5 (d-f) was gender specific, with significant deceleration of height (change 11 to $15=-0.58 ; p<.001$ ) and weight (change 11 to $15=-0.53 ; p<.001)$ seen only in girls with more than 6 months of institutional deprivation. Similar to figure 7.5f, girls did not show additional catch-up growth of head circumference after age 11 years, independent of institutional deprivation $(p s>.15)$, whereas catch-up growth continued 
after age 11 in boys in the institution rearing $>6$ months group, but not in the comparison group (comparison group: $p=.020 ;>6 \mathrm{M}$ group: $p=.001$ ).

\section{$<$ H1 $>$ Discussion and Conclusions}

It has generally been accepted that the effects of early institutional deprivation on physical growth, although potentially profound, are only temporary, with catch-up occurring over childhood and adolescence, even in those individuals suffering the longest periods of deprivation (van IJzendoorn et al., 2007). These conclusions have been reached on the basis of cross-sectional data - clearly longitudinal data are required to provide a definitive answer to the question of growth 'catch-up'. Our previous analyses of longitudinal data up to 11 years generally supported this picture for height and weight, whereas for head circumference there was considerable catchup, but individuals suffering extended deprivation still had substantially smaller heads than the norm as they entered adolescence (Sonuga-Barke et al., 2008). This general picture needs to be revised in the light of the results of the analyses reported here.

First, the apparent normalization of height and weight by 11 years following significant catch-up in the $>6 \mathrm{M}$ group seems to have been a transient phenomenon, rather than permanent catch-up. Growth acceleration seen between 6 and 11 years was followed by an equal and opposite period of growth deceleration in those experiencing deprivation beyond the age of 6 months. Second, this pattern was not limited to those who had experienced subnourishment, with both subnourished and non-subnourished individuals in the $>6 \mathrm{M}$ group showing the characteristic pattern despite the large overall effect of sub-nourishment on growth. Whereas this suggests that psychosocial factors are implicated in both the deprivation-related growth trajectory and also the overall level of stunting, we must recognize that our definition of subnourishment was based on weight at entry and, although this probably reflects the calorific intake in the 
period prior to adoption, we did not measure different dietary insufficiencies or dietary balance. It is also possible that children who were not subnourished prior to adoption had experienced some period of subnourishment earlier on in their institutionalization.

This raises the interesting possibility that what has, in the past, been interpreted as a process of growth catch-up, might be better characterized as a pre-adolescent growth spurt, the temporary effects of which, seen as growth normalizes, will be lost as the population as a whole reaches the age for the 'normal' growth spurt. The persistent effects on physical growth highlight the long-term effect of severe early deprivation on biological systems generally, rather than just on neurobiological systems specifically. It is, therefore, interesting that, although there were similar trajectories for DSP+ and DSP-groups, the largest overall effects were found in the $\mathrm{DSP}+$ group. One possibility is that growth stunting represents a marker for the overall severity of deprivation-related risk experienced by the institutionalized children or the degree of biological vulnerability to early adversity of a particular individual.

The effects of deprivation on height and weight were similarly large at age 15, where the effects for head circumference were, if anything, more substantial and took a different form, with linear like increases across ages in all groups. Once more, the most significant effects were seen in the DSP+ group, highlighting the potential role of brain stunting in the etiology of DSPs. These effects were observed even in the absence of subnutrition - reinforcing the view that psychosocial, as well as nutritional, risks can produce fundamental alterations in brain size. Psychosocial deprivation appears to have a pervasive effect across biological and psychological systems, independent of the nutritional risk often associated with institutional living (but see comment about measuring subnutrition). Our mediational analyses supported this 
view. The indirect path via head circumference, although less important than the direct pathway, still accounted for around $20 \%$ of the effects. This contrasted with our previous analysis of age 11 data (Sonuga-Barke et al., 2008) where we failed to find that these gross reductions in brain volume played a role in mediating the biological risk associated with institutional deprivation on intellectual impairment and psychopathology. There are a number of possible reasons for this difference. As well as having data of growth through to 15 years, we also adopted a different approach to characterizing outcomes. We attempted to differentiate those components of outcomes that we could be fairly confident were deprivation specific by using the definition from chapter 3 (Kumsta, Kreppner et al.). It is important to recognize that these effects may overlap with, or be independent of, the more subtle and specific effects in relation to the limbic system described in the introduction (Mehta et al., 2009).

The discussion on the effects of puberty necessarily must start with the evidence that institutional deprivation was indeed associated with a significantly earlier pubertal maturation, a difference of some one third of a standard deviation on the Tanner scale dimensional measure. This translated into an odds ratio of about 1.8 for the categorical measure of early puberty. The next issue is whether this earlier puberty in the group experiencing institutional deprivation until after the age of 6 months might have had an effect on height, weight and head circumference. We lacked the statistical power to undertake adequate statistical testing, but the growth trajectories for our analyses suggest that the 'growth-spike' phenomenon might be associated with early puberty. There was a sub-group of participants who showed early puberty-related catch-up growth that had already manifested itself at age 6 years, but did so more completely at age 11 . However, those adolescents who had spent 
more than 6 months in a Romanian institution fell behind population growth norms between age 11 and 15 . Interestingly, this puberty-related early accelerationdeceleration pattern did not vary by the presence or absence of DSPs.

Our gender-specific analysis supported the notion of the accelerationdeceleration pattern being related to puberty and institutional deprivation. As girls generally reach puberty earlier than boys (a pattern verified for our participants in the comparison group), the observation of the deceleration effect being significant only in girls of the $>6 \mathrm{M}$ group suggests that institutional deprivation combined with early puberty is associated with decelerated growth later in life in some adolescents. Although the underlying mechanisms for these growth patterns are unclear, our findings are consistent with the notion of differential allocation of resources, favoring growth and reproduction relatively early in life over growth later in life in individuals who experienced severe deprivation very early in life.

In summary, the results reported in this chapter lead us to reconsider our previous conclusion about the impact of institutional deprivation on physical growth. First, there were markedly different patterns of growth for $>6 \mathrm{M}$ group with a rapid acceleration in growth between 6 and 11 years and equally marked deceleration between 11 and 15 years suggestive of a growth spurt rather than developmental catch-up. Strikingly, the $<6 \mathrm{M}$ group displayed the pattern expected in non-deprived samples. Second, whereas this pattern was similar for DSP+ and DSP-, overall stunting was more marked in the DSP+ group. The characteristic pattern of growth acceleration and deceleration was most characteristic of those individuals who had an early puberty, which was more common in the over 6 month group. There was no growth spurt in relation to head circumference, but effects once again were more marked in the DSP+ group. Growth stunting was observed even in the absence of 
subnutrition. Reduced head circumference as a marker of brain growth partially mediated the link between duration of deprivation and DSP. Institutional deprivation has a pervasive and interrelated effect across body, brain and behavioral systems that persisted for a substantial sub-group of children who experienced more than 6 months deprivation. The data highlight the power of the psychosocial environment to shape biology and, by doing so, determine long term behavioral and intellectual outcomes. The impact of deprivation on puberty warrants further study using more sensitive measures and powerful analysis. In particular the role of the combination of early institutional deprivation followed by adoption to well functioning and nurturing homes will need further consideration although this is beyond the scope of the current sample.

\section{$<$ H1 $>$ References}

Aksglaede, L., Olsen, L. W., Sorensen, T. I., \& Juul, A. (2008). Forty years trends in timing of pubertal growth spurt in 157,000 Danish school children. PLoS ONE, 3, e2728.

Baron, S., Battin, J., David, A., \& Limal, J. M. (2000). Early pubertal development in children adopted from abroad. Archives De Pediatrie, 7, 809-816.

Belsky, J., Steinberg, L. D., Houts, R. M., Friedman, S. L., DeHart, G., Cauffman, E., et al. (2007). Family rearing antecedents of pubertal timing. Child Development, 78, 1302-1321.

Bremner, J. D. (1999). Alterations in brain structure and function associated with post-traumatic stress disorder. Seminars in Clinical Neuropsychiatry, 4, 249255.

Bremner, J. D. (2001). Hypotheses and controversies related to effects of stress on the hippocampus: an argument for stress-induced damage to the hippocampus in 
patients with posttraumatic stress disorder. Hippocampus, 11, 75-81; discussion 82-74.

Bremner, J. D. (2007). Neuroimaging in posttraumatic stress disorder and other stressrelated disorders. Neuroimaging Clinics of North America, 17, 523-528.

Bremner, J. D., Elzinga, B., Schmahl, C., \& Vermetten, E. (2008). Structural and functional plasticity of the human brain in posttraumatic stress disorder. Stress Hormones and Post Traumatic Stress Disorder: Basic Studies and Clinical Perspectives, 167, 171-178.

Bremner, J. D., Randall, P., Scott, T. M., Bronen, R. A., Seibyl, J. P., Southwick, S. M., et al. (1995). MRI-based measurement of hippocampal volume in patients with combat-related posttraumatic-stress-disorder. American Journal of Psychiatry, 152, 973-981.

Bremner, J. D., Randall, P., Vermetten, E., Staib, L., Bronen, R. A., Mazure, C., et al. (1997). Magnetic resonance imaging-based measurement of hippocampal volume in posttraumatic stress disorder related to childhood physical and sexual abuse - A preliminary report. Biological Psychiatry, 41, 23-32.

Castle, J., Groothues, C., Bredenkamp, D., Beckett, C., O'Connor, T., \& Rutter, M. (1999). Effects of qualities of early institutional care on cognitive attainment. E.R.A. Study Team. English and Romanian Adoptees. American Journal of Orthopsychiatry, 69, 424-437.

Chugani, H. T., Behen, M. E., Muzik, O., Juhasz, C., Nagy, F., \& Chugani, D. C. (2001). Local brain functional activity following early deprivation: A study of postinstitutionalized Romanian orphans. Neuroimage, 14, 1290-1301.

De Bellis, M. D., Keshavan, M. S., Shifflett, H., Iyengar, S., Beers, S. R., Hall, J., et al. (2002). Brain structures in pediatric maltreatment-related posttraumatic 
stress disorder: A sociodemographically matched study. Biological Psychiatry, $52,1066-1078$.

de Kloet, E. R., Sibug, R. M., Helmerhorst, F. M., \& Schmidt, M. (2005). Stress, genes and the mechanism of programming the brain for later life. Neuroscience and Biobehavioral Reviews, 29, 271-281.

Domene, H. M., Scaglia, P. A., Lteif, A., Mahmud, F. H., Kirmani, S., Frystyk, J., et al. (2007). Phenotypic effects of null and haploinsufficiency of acid-labile subunit in a family with two novel IGFALS gene mutations. Journal of Clinical Endocrinology and Metabolism, 92, 4444-4450.

Eluvathingal, T. J., Chugani, H. T., Behen, M. E., Juhasz, C., Muzik, O., Maqbool, M., et al. (2006). Abnormal brain connectivity in children after early severe socioemotional deprivation: A diffusion tensor imaging study. Pediatrics, 117, 2093-2100.

Golden, M. H. (1994). Is complete catch-up possible for stunted malnourished children? European Journal of Clinical Nutrition, 48 Suppl 1, S58-70.

Graham, G. C., \& Adrianzen, B. A. (1972). Late "catch-up" growth after severe infantile subnutrition. Hopkins Medical Journal, 131, 203- 212.

Hayakawa, K., Konishi, Y., Matsuda, T., Kuriyama, M., Konishi, K., Yamashita, K., et al. (1989). Development and Aging of Brain Midline Structures Assessment with Mr Imaging. Radiology, 172, 171-177.

Hulanicka, B., Gronkiewicz, L., \& Koniarek, J. (2001). Effect of familial distress on growth and maturation of girls: A longitudinal study. American Journal of Human Biology, 13, 771-776.

Ivanovic, D. M., Leiva, B. P., Perez, H. T., Olivares, M. G., Diaz, N. S., Urrutia, M. S., et al. (2004). Head size and intelligence, learning, nutritional status and 
brain development. Head, IQ, learning, nutrition and brain. Neuropsychologia, $42,1118-1131$.

Juffer, F., \& van IJzendoorn, M.H. (2009). International adoption comes of age: Development of international adoptees from a longitudinal and meta-analytic perspective. In: G.M. Wrobel \& E. Neil (Eds.), International advances in adoption research for practice. Chichester, UK: Wiley-Blackwell. 169-192.

Karl, A., Schaefer, M., Malta, L. S., Dorfel, D., Rohleder, N., \& Werner, A. (2006). A meta-analysis of structural brain abnormalities in PTSD. Neuroscience and Biobehavioral Reviews, 30, 1004-1031.

Kaufman, J., Plotsky, P. M., Nemeroff, C. B., \& Charney, D. S. (2000). Effects of early adverse experiences on brain structure and function: Clinical implications. Biological Psychiatry, 48, 778-790.

Kreppner, J. M., Rutter, M., Beckett, C., Castle, J., Colvert, E., Groothues, C., et al. (2007). Normality and impairment following profound early institutional deprivation: a longitudinal follow-up into early adolescence. Developmental Psychology, 43, 931-946.

Leon-Carrion, J., Atutxa, A. M., Mangas, M. A., Soto-Moreno, A., Pumar, A., LeonJustel, A., et al. (2009). A clinical profile of memory impairment in humans due to endogenous glucocorticoid excess. Clinical Endocrinology, 70, 192200.

Levitsky, D. A. (Ed.) (1979). Subnutrition and the hunger to learn. In: Malnutrition, environment and behavior: New perspectives. Ithaca, N.Y: Cornell University Press.

Liu, J. H., \& Raine, A. (2006). The effect of childhood malnutrition on externalizing behavior. Current Opinion in Pediatrics, 18, 565-570. 
Liu, J. H., Raine, A., Venables, P. H., Dalais, C., \& Mednick, S. A. (2003).

Malnutrition at age 3 years and lower cognitive ability at age 11 years: Independence from psychosocial adversity. Archives of Pediatrics and Adolescent Medicine, 157, 593-600.

Liu, J. H., Raine, A., Venables, P. H., \& Mednick, S. A. (2004). Malnutrition at age 3 years and externalizing behavior problems at ages 8,11 , and 17 years. American Journal of Psychiatry, 161, 2005-2013.

Martorell, R., Khan, L. K., \& Schroeder, D. G. (1994). Reversibility of stunting: epidemiological findings in children from developing countries. European Journal of Clinical Nutrition, 48 Suppl 1, S45-57.

Mehta, M. A., Golembo, N. I., Nosarti, C., Colvert, E., Mota, A., Williams, S. C. R., et al. (2009). Amygdala, hippocampal and corpus callosum size following severe early institutional deprivation: The English and Romanian Adoptees study. Journal of Child Psychology and Psychiatry, 50, 943-951.

Mrug, S., Elliott, M., Gilliland, M. J., Grunbaum, J. A., Tortolero, S. R., Cuccaro, P., et al. (2008). Positive parenting and early puberty in girls - Protective effects against aggressive behavior. Archives of Pediatrics \& Adolescent Medicine, $162,781-786$

Nelson, C. A. (1999). Neural plasticity and human development. Current Directions in Psychological Science, 8, 42-45.

Nishida, M., Makris, N., Kennedy, D. N., Vangel, M., Fischl, B., Krishnamoorthy, K. S., et al. (2006). Detailed semiautomated MRI based morphometry of the neonatal brain: Preliminary results. Neuroimage, 32, 1041-1049.

Pears, K., \& Fisher, P. A. (2005). Developmental, cognitive, and neuropsychological functioning in preschool-aged foster children: Associations with prior 
maltreatment and placement history. Journal of Developmental and Behavioral Pediatrics, 26, 112-122.

Pfluger, T., Weil, S., Weis, S., Vollmar, C., Heiss, D., Egger, J., et al. (1999). Normative volumetric data of the developing hippocampus in children based on magnetic resonance imaging. Epilepsia, 40, 414-423.

Posner, R. B. (2006). Early menarche: A review of research on trends in timing, racial differences, etiology and psychosocial consequences. Sex Roles, 54, 315-322.

Rosenzweig, M. R., \& Bennett, E. L. (1996). Psychobiology of plasticity: Effects of training and experience on brain and behavior. Behavioural Brain Research, $78,57-65$.

Rutter, M., Beckett, C., Castle, J., Colvert, E., Kreppner, J., Mehta, M., et al. (2007). Effects of profound early institutional deprivation: An overview of findings from a UK longitudinal study of Romanian adoptees. European Journal of Developmental Psychology, 4, 332-350.

Rutter, M., \& O’Connor, T. G. (2004). Are there biological programming effects for psychological development? Findings from a study of Romanian adoptees. Developmental Psychology, 40, 81-94.

Sonuga-Barke, E. J., Beckett, C., Kreppner, J., Castle, J., Colvert, E., Stevens, S., et al. (2008). Is subnutrition necessary for a poor outcome following early institutional deprivation? Developmental Medicine and Child Neurology, 50, $664-671$.

Stoch, M. B., Smythe, P. M., Moodie, A. D., \& Bradshaw, D. (1982). Psychosocial outcome and CT findings after gross undernourishment during infancy: a 20year developmental study. Developmental medicine and child neurology, 24, $419-436$. 
Suomi, S. J. (1997). Long-term effects of different early rearing experiences on social, emotional, and physiological development in non-human primates. In: M. S. Keshevan \& R. M. Murray (Eds.), Neurodevelopment and adult psychopathology (peer problems. 104-116). Cambridge, UK: Cambridge University Press.

Teicher, M. H., Andersen, S. L., Polcari, A., Anderson, C. M., Navalta, C. P., \& Kim, D. M. (2003). The neurobiological consequences of early stress and childhood maltreatment. Neuroscience and Biobehavioral Reviews, 27, 33-44.

Teicher, M. H., Dumont, N. L., Ito, Y., Vaituzis, C., Giedd, J. N., \& Andersen, S. L. (2004). Childhood neglect is associated with reduced corpus callosum area. Biological Psychiatry, 56, 80-85.

Tottenham, N., Hare, T., Quinn, B., McCarry, T., Nurse, M., Gilhooly, T., et al. (in press). Prolonged institutional rearing is associated with atypically larger amygdala volume and difficulties in emotion regulation. Developmental Science.

Tupler, L. A., \& De Bellis, M. D. (2006). Segmented hippocampal volume in children and adolescents with posttraumatic stress disorder. Biological Psychiatry, 59, 523-529.

Van IJzendoorn, M. H., Bakermans-Kranenburg, M. J., \& Juffer, F. (2007). Plasticity of growth in height, weight, and head circumference: Meta-analytic evidence of massive catch-up after international adoption. Journal of Developmental and Behavioral Pediatrics, 28, 334-343.

Vythilingam, M., Luckenbaugh, D. A., Lam, T., Morgan, C. A., Lipschitz, D., Charney, D. S., et al. (2005). Smaller head of the hippocampus in Gulf War- 
related posttraumatic stress disorder. Psychiatry Research-Neuroimaging, 139, 89-99. 
TABLE 7.1: Weight, height and head circumference $s d$-scores in participants with more than 6 months institutional deprivation $v s$. a pooled comparison group, layered by gender and assessment wave.

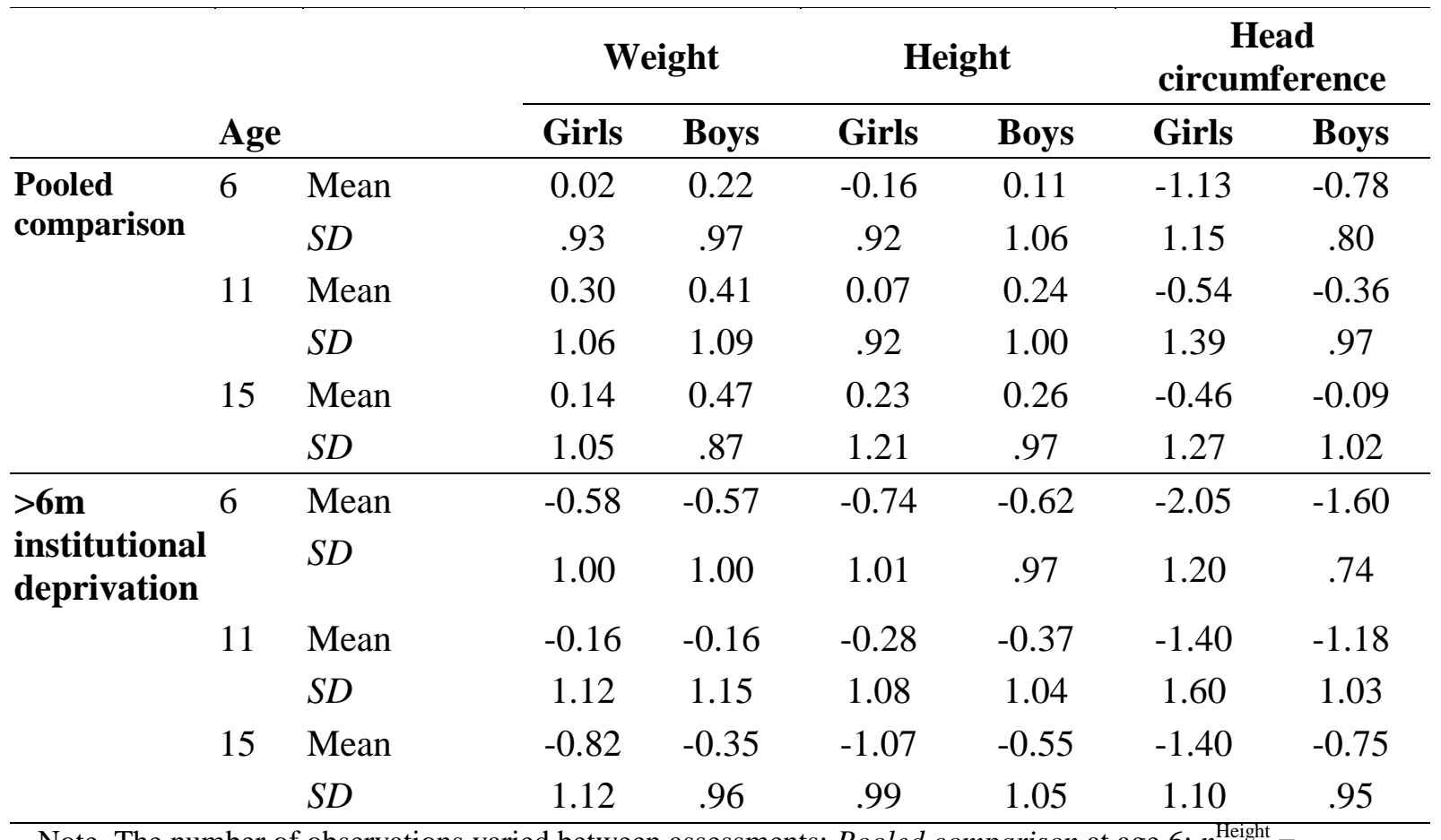

Note. The number of observations varied between assessments: Pooled comparison at age 6: $n^{\text {Height }}=$ 111, $n^{\text {Weight }}=111, n^{\mathrm{HC}}=111$; age 11: $n^{\text {Height }}=109, n^{\text {Weight }}=109, n^{\text {HC }}=109$, age 15: $n^{\text {Height }}=90, n^{\text {Weight }}=$ $93, n^{\mathrm{HC}}=96 .>6 m$ institutional deprivation at age $6: n^{\text {Height }}=87, n^{\text {Weight }}=87, n^{\mathrm{HC}}=86$; age 11: $n^{\text {Height }}=$ $84, n^{\text {Weight }}=84, n^{\mathrm{HC}}=85$; age $15: n^{\text {Height }}=61, n^{\text {Weight }}=61, n^{\mathrm{HC}}=72$. 
TABLE 7.2: Height, weight and head circumference ( $s d$-scores) for three groups.

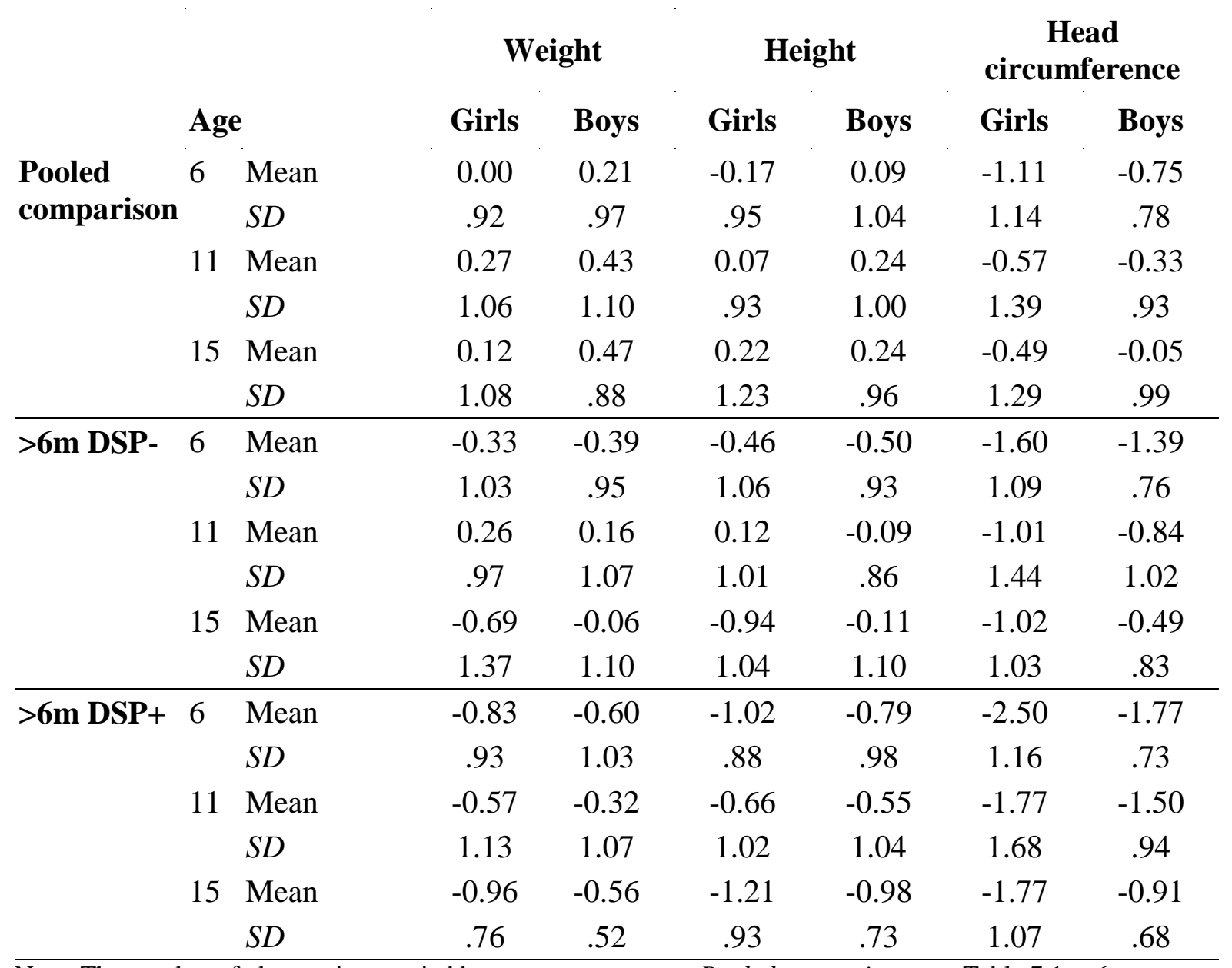

Note. The number of observations varied between assessments: Pooled comparison: see Table 7.1. $>6 \mathrm{~m}$ DSP- at age 6: $n^{\text {Height }}=46, n^{\text {Weight }}=46, n^{\mathrm{HC}}=46$; age 11: $n^{\text {Height }}=43, n^{\text {Weight }}=44, n^{\mathrm{HC}}=44$, age 15:

$n^{\text {Height }}=34, n^{\text {Weight }}=34, n^{\mathrm{HC}}=37 .>6 m D S P+$ at age 6: $n^{\text {Height }}=41, n^{\text {Weight }}=41, n^{\mathrm{HC}}=40 ;$ age $11: n^{\text {Height }}$ $=41, n^{\text {Weight }}=41, n^{\mathrm{HC}}=41$; age $15: n^{\text {Height }}=27, n^{\text {Weight }}=27, n^{\mathrm{HC}}=35$. 
TABLE 7.3: Subnutrition at entry to the UK by DSP, $>6 \mathrm{~m}$ Romanians only.

\begin{tabular}{lllccc}
\hline & & \multicolumn{3}{c}{ DSP } & \\
\cline { 3 - 4 } & & & No & Yes & Total \\
\hline Subnutrition & No & Frequency & 12 & 11 & 23 \\
& & Total \% & $32.4 \%$ & $33.3 \%$ & $32.9 \%$ \\
& Yes & Frequency & 25 & 22 & 47 \\
& & Total \% & $67.6 \%$ & $66.7 \%$ & $67.1 \%$ \\
\hline \multirow{2}{*}{ Total } & Frequency & 37 & 33 & 70 \\
& Total \% & $100.0 \%$ & $100.0 \%$ & $100.0 \%$ \\
\hline
\end{tabular}


TABLE 7.4: Frequency of puberty indicators (see text) in the three groups (see text for details). Percentage reflects proportion of non-missing values within groups.

\begin{tabular}{lccc}
\hline Group & $\begin{array}{c}\text { Stage of } \\
\text { puberty at age } \\
\text { 11 years } \\
\text { Mean }(S D)\end{array}$ & \multicolumn{2}{c}{$\begin{array}{c}\text { Onset of puberty } \\
\text { Frequency }(\%)\end{array}$} \\
\cline { 3 - 4 } $\begin{array}{l}\text { Pooled } \\
\text { comparison }\end{array}$ & $3.38(1.55)$ & $19(17 \%)$ & $93(83 \%)$ \\
\hline Total >6M & $4.02(2.06)$ & $23(27 \%)$ & $62(73 \%)$ \\
\hline$>6$ M DSP- & $4.04(1.98)$ & $12(27 \%)$ & $33(73 \%)$ \\
>6M DSP+ & $4.00(2.17)$ & $11(28 \%)$ & $29(73 \%)$ \\
\hline
\end{tabular}


FIGURE 7.1: Trajectories for height, weight and head circumference ( $s d$-scores) in participants with more than 6 months institutional deprivation $v s$. a pooled comparison group. For number of observation see Table 7.1.

(A)

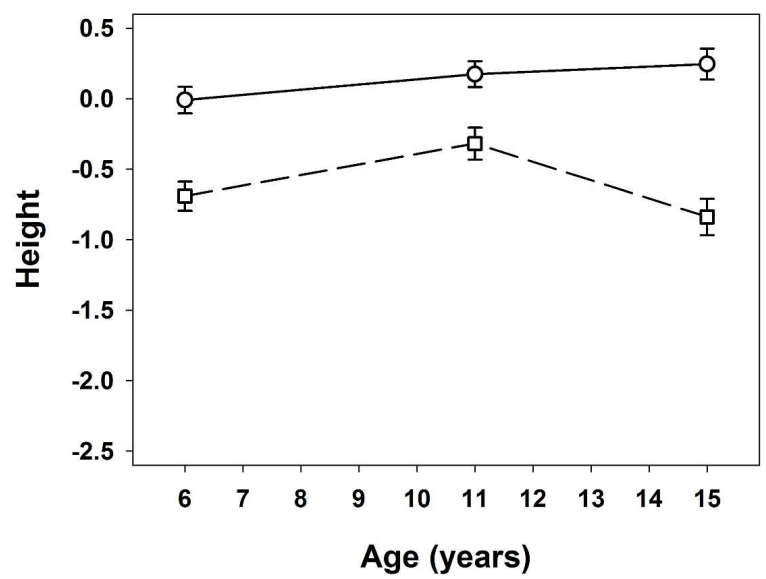

(C)

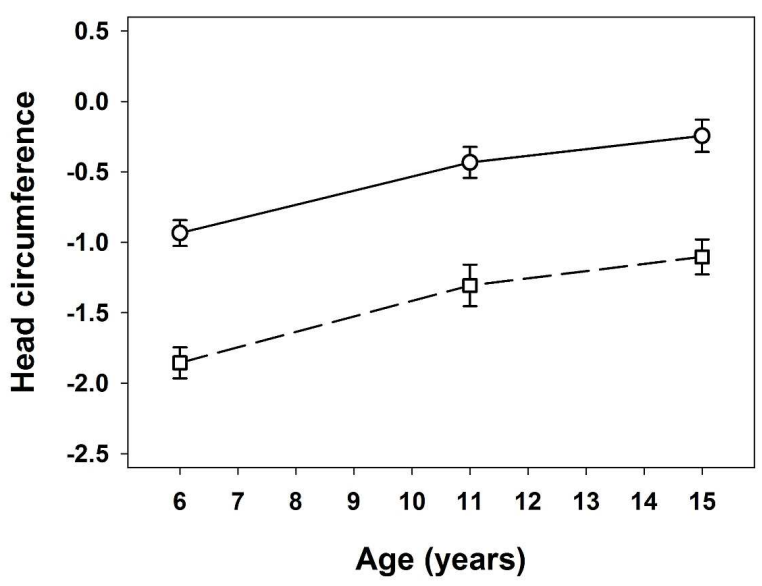

(B)

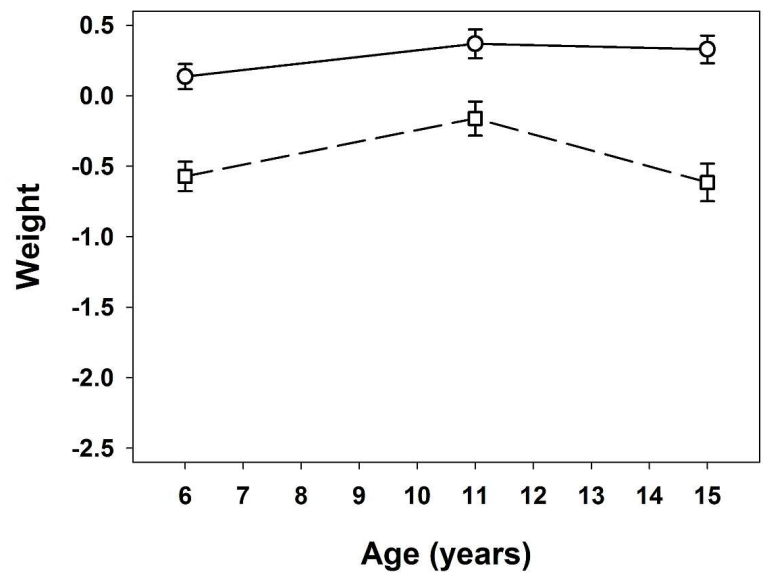

- Comparison group

$-\neg->6$ months ID 
FIGURE 7.2: Height, weight and head circumference ( $s d$-scores) for comparison $v s$. DSP- v DSP+ group. For number of observations see Table 7.2.

(A)

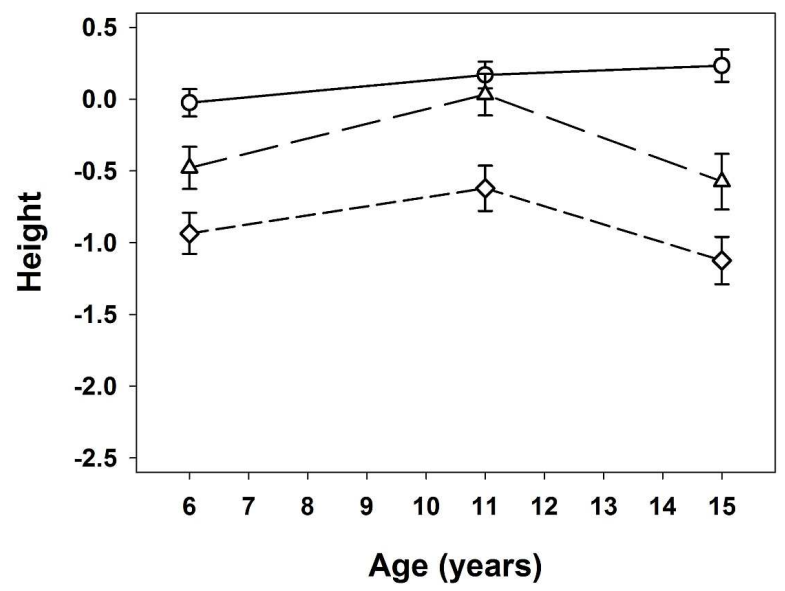

(C)

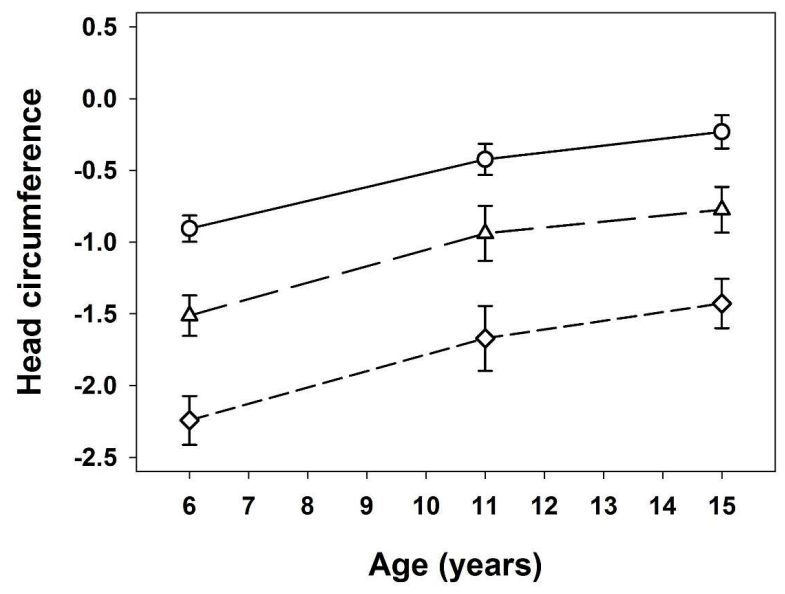

(B)

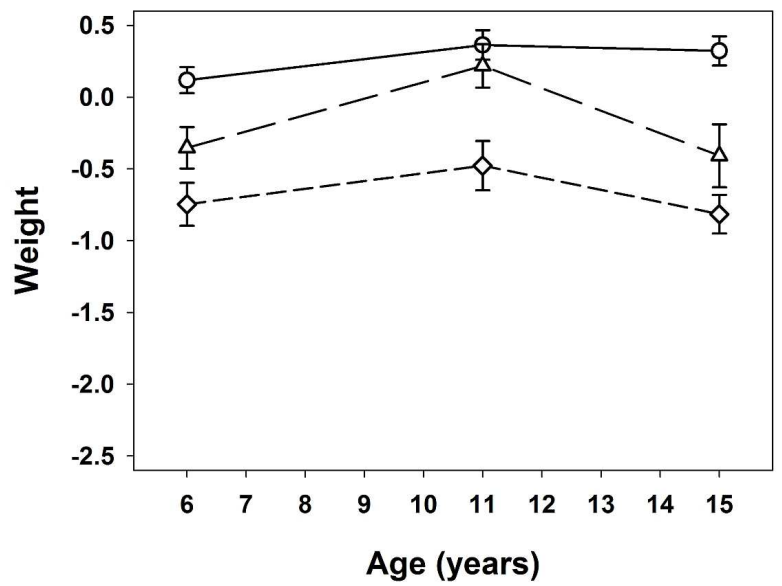

Age (years)

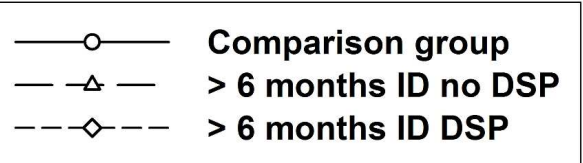


FIGURE 7.3: Height (A and D), weight (B and E) and head circumference (C and F) $s d$-scores for three groups (within-UK adoptees excluded) by subnutrition (no: left hand side; yes: right hand side). Number of observations varied by outcome and age. Not subnourished: comparison group range of $n=22-29$; no DSP range of $n=11-12$; DSP range of $n=5-11$. Subnourished: comparison group range of $n=23-31$; no DSP range of $n=18-24$; DSP range of $n=14-22$.

Not subnourished

(A)

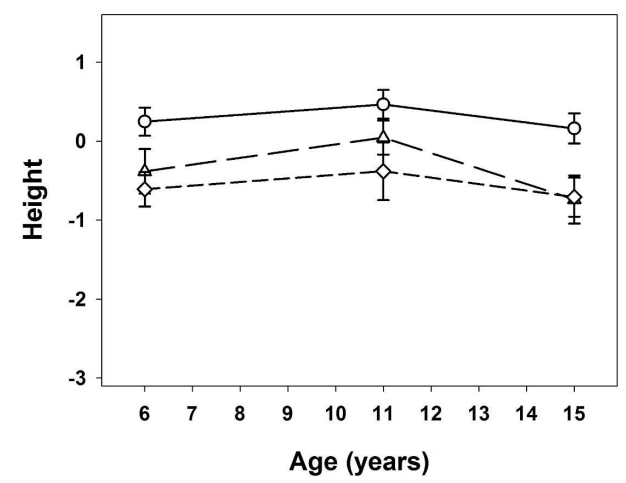

(B)

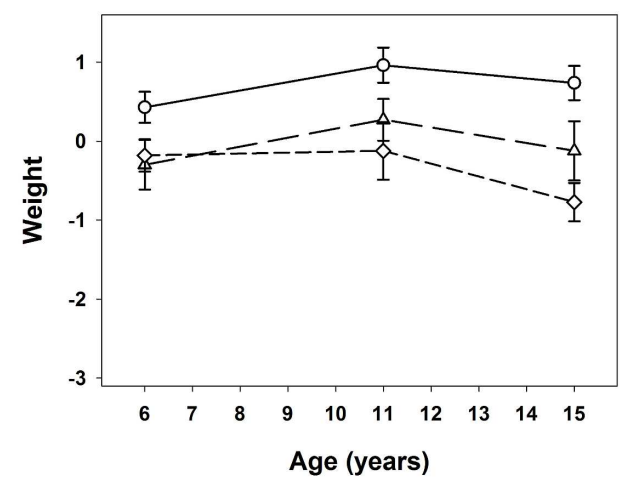

(C)

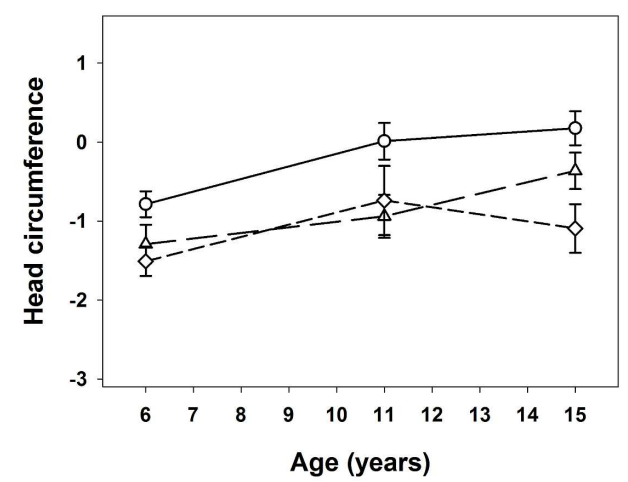

Subnourished

(D)

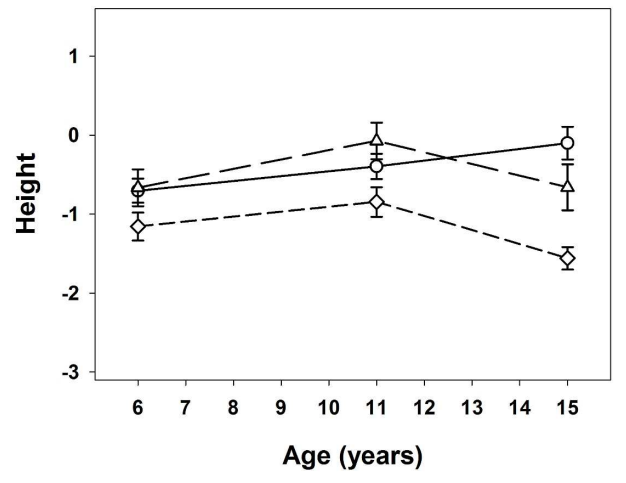

(E)

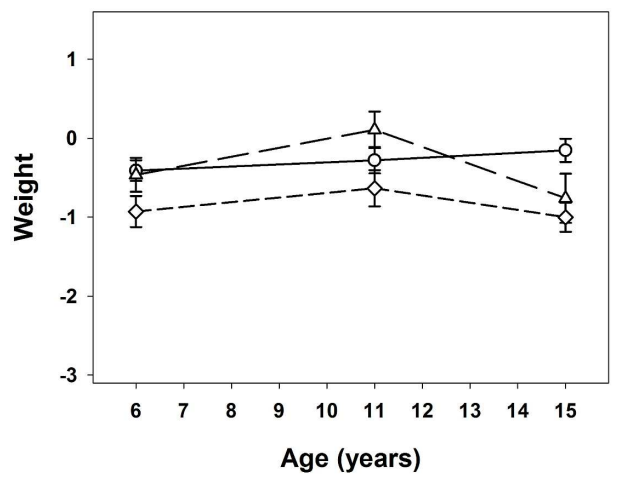

(F)

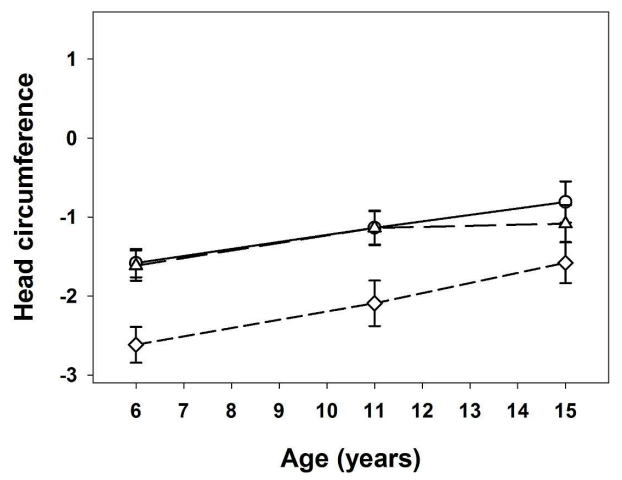

$$
\begin{array}{ll}
\longrightarrow-\infty & \text { Comparison group } \\
--\downarrow- & >6 \text { months ID no DSP } \\
--\diamond-- & >6 \text { months ID DSP }
\end{array}
$$


FIGURE 7.4: Results of path analyses for the mediation of the effect of duration of deprivation on deprivation-specific problems via head circumference at age 6 years.

(A) $(n=196)$

$\underline{\text { Initial Direct Path } b=1.32^{* * *}}$

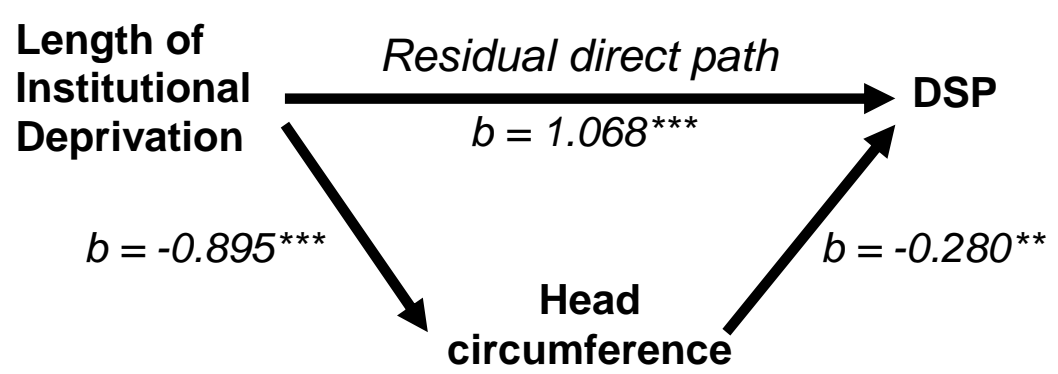

Indirect effect $b=0.250^{*}$

(B) $(n=196)$

$\underline{\text { Initial Direct Path } b=1.37^{* *}}$

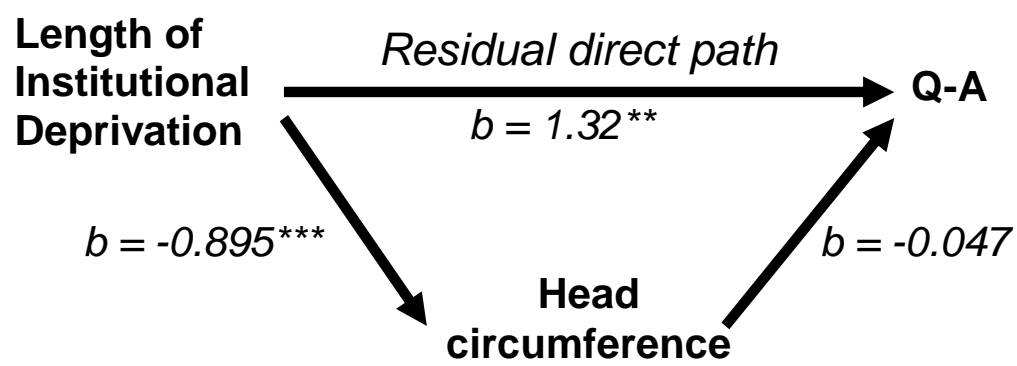

Indirect effect $b=0.042$

(C) $(n=196)$

$\underline{\text { Initial Direct Path } b=1.24^{\star \star *}}$

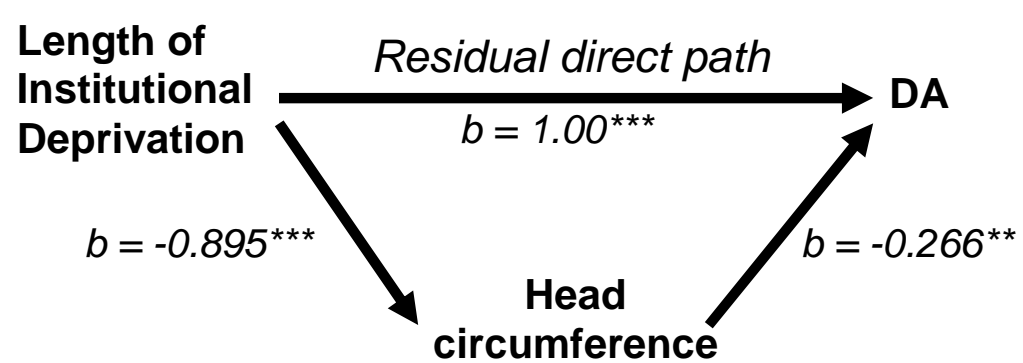

Indirect effect $b=0.238^{*}$

$* p<.05, * * p<.01, * * * p<.001$ 
FIGURE 7.5: Growth in height (A and D), weight (B and E) and head circumference $(\mathrm{C}$ and $\mathrm{F})$ in adolescents that had reached puberty by age 11 years (right hand side) $\mathrm{V}$ those that had not (left hand side). Number of observations varied by outcome and age. No puberty at age 11: comparison group range of $n=70-89$; no DSP range of $n=$ 25-30; DSP range of $n=24-29$. Puberty at age 11: comparison group range of $n=17$ 19; no DSP range of $n=8-12$; DSP range of $n=3-11$.

No puberty at age 11 years

(A)

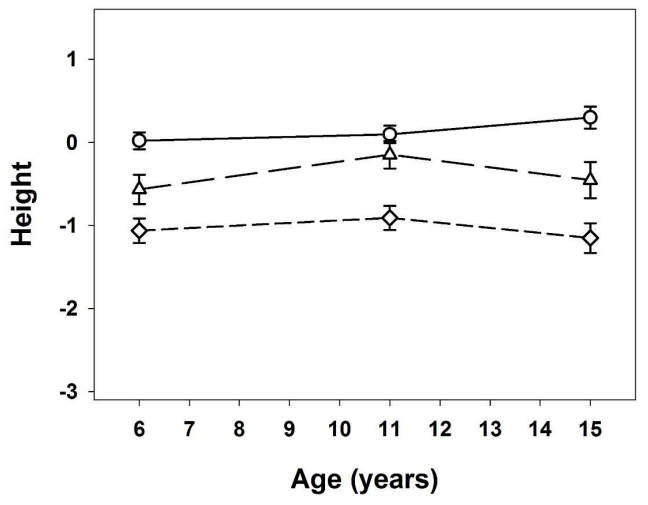

(B)

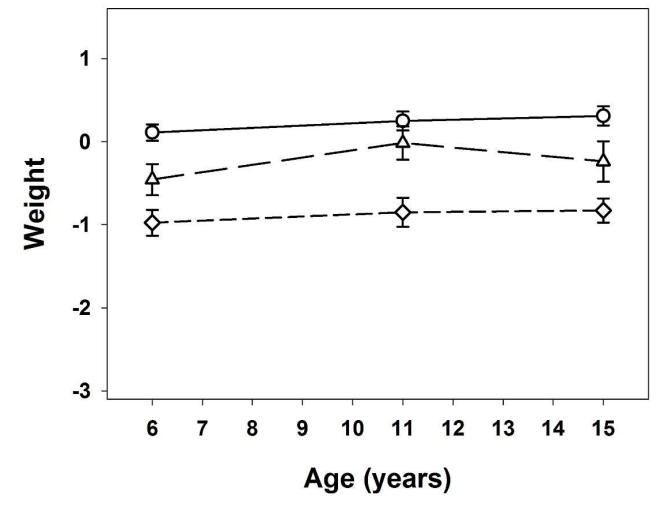

(C)

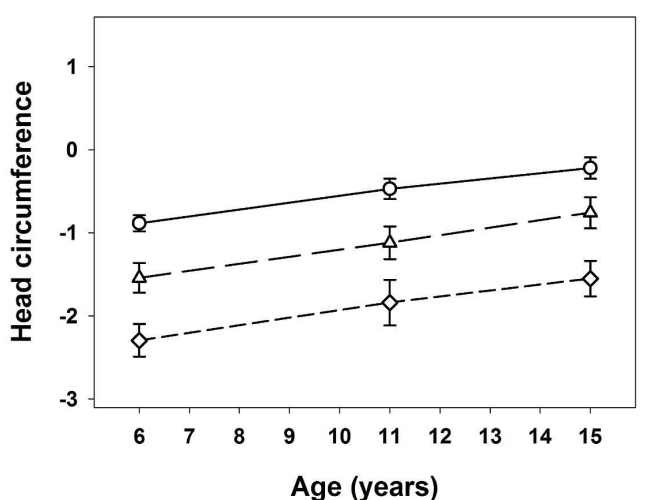

Puberty at age 11 years

(D)

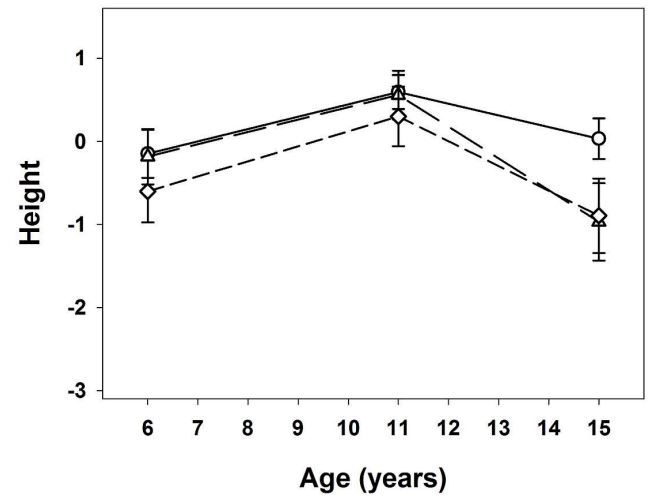

(E)

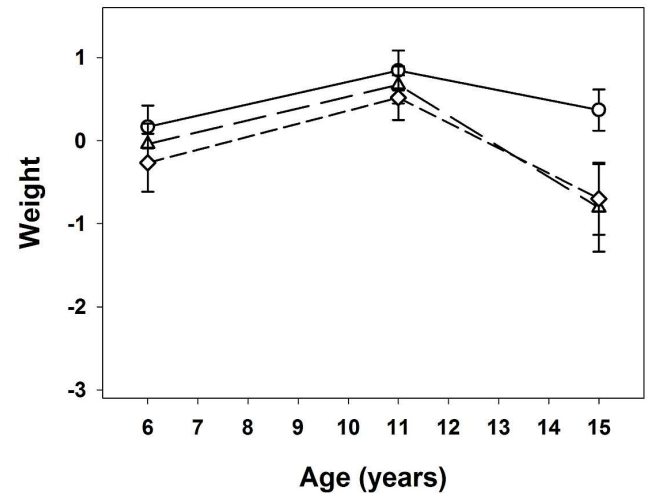

(F)

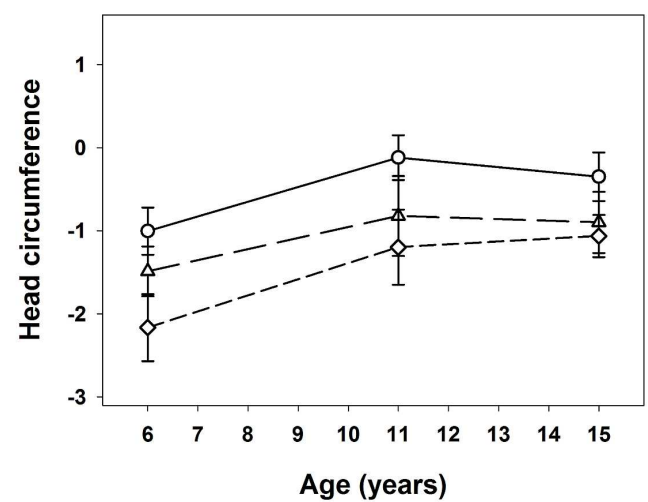
$\begin{array}{ll}-0 \_ & \text {Comparison group } \\ --\_- & >6 \text { months ID no DSP } \\ --\diamond-- & >6 \text { months ID DSP }\end{array}$ 